SUPPLEMENTARY MATERIAL

Three new resin glycosides compounds from Argyreia acuta and their $\alpha$-glucosidase inhibitory activity

Li Wang, You-ShaoYan, Hong-Hua Cui ${ }^{\dagger}$, Yong-Qin Yin ${ }^{\ddagger}$ Jie-Tao Pan, Bang-Wei Yu

Department of Traditional Chinese Medicinal Chemistry, Guangdong Pharmaceutical University, Guangzhou 510006, People's Republic of China

${ }^{\dagger}$ Corresponding author. Email: honghuacui@ 163.com

* Corresponding author. Email: yongqinyin@126.com 


\title{
Three new resin glycosides compounds from Argyreia acuta and their $\alpha$-glucosidase inhibitory activity
}

\begin{abstract}
Three new phenolic compounds, acutacoside C (1), acutacoside D (2), and acutacoside E (3) were isolated from the airial part of Argyreia acuta. The oligosaccharide chain was composed with two glucoses and three rhamnoses, and the aglycone was (11S)-hydroxyhexadecanoic acid (jalapinolic acid). The core of the three compounds was operculinic acid B, which was rare in resin glycosides. Their structures were established by a combination of spectroscopic and chemical methods. Compounds 1-3 have been evaluated for inhibitory activity against $\alpha$-glucosidase, which all showed weak inhibitory activities.
\end{abstract}

Keywords: Argyreia acuta, resin glycosides, structural identification, $\alpha$-glucosidase 
Table S1. NMR Data for Compounds 1-3 in pyridine- $d_{5}$.

\begin{tabular}{|c|c|c|c|c|c|c|}
\hline \multirow{2}{*}{ Position } & \multicolumn{2}{|r|}{1} & \multicolumn{2}{|r|}{2} & \multicolumn{2}{|r|}{3} \\
\hline & ${ }^{13} \mathrm{C}$ & ${ }^{1} \mathbf{H}$ & ${ }^{13} \mathrm{C}$ & ${ }^{1} \mathbf{H}$ & $\overline{{ }^{13} \mathrm{C}}$ & ${ }^{1} \mathbf{H}$ \\
\hline Glu-1 & 104.2 & $5.03 \mathrm{~d}(7.5)$ & 104.4 & $5.12 \mathrm{~d}(8.0)$ & 104. & $4.93 \mathrm{~d}(6.5)$ \\
\hline 2 & 81.7 & $3.93 *$ & 82.0 & $3.89 *$ & 82.0 & $3.93 *$ \\
\hline 3 & 76.3 & $4.29 *$ & 76.6 & $4.19^{*}$ & 76.6 & $4.20^{*}$ \\
\hline 4 & 71.6 & $4.24 *$ & 71.8 & $4.14^{*}$ & 71.8 & $4.14^{*}$ \\
\hline 5 & 77.8 & $3.97 *$ & 78.0 & $3.87 *$ & 78.0 & $3.87 *$ \\
\hline 6 & 62.6 & $\begin{array}{l}4.42 * \\
4.59 *\end{array}$ & 62.8 & $\begin{array}{l}4.31 * \\
4.47 *\end{array}$ & 62.8 & $\begin{array}{l}4.33 * \\
4.49 *\end{array}$ \\
\hline Rha-1 & 98.3 & $5.71 \mathrm{br} \mathrm{s}$ & 98.6 & 5.61 br s & 98.5 & 5.62 br s \\
\hline 2 & 73.3 & 6.15 br s & 73.5 & $6.06 \mathrm{br} \mathrm{s}$ & 73.5 & 6.05 br s \\
\hline 3 & 69.1 & $5.18 \mathrm{dd}(9.5,3.5)$ & 69.5 & $5.07 \mathrm{dd}(9.0,3.5)$ & 69.3 & $5.08 \mathrm{dd}(9.5,3.5)$ \\
\hline 4 & 81.7 & $4.31 \mathrm{dd}(9.5,9.5)$ & 81.0 & $4.21 \mathrm{dd}(9.0,9.0)$ & 82.0 & $4.21 \mathrm{dd}(9.5,9.5)$ \\
\hline 5 & 68.8 & $4.49^{*}$ & 69.0 & $4.37^{*}$ & 69.1 & $4.39 *$ \\
\hline 6 & 18.9 & $1.72 \mathrm{~d}(6.0)$ & 19.2 & $1.62 \mathrm{~d}(6.0)$ & 19.1 & $1.62 \mathrm{~d}(6.0)$ \\
\hline Rha'-1 & 100.0 & 5.99 br s & 99.7 & 6.34 br s & 100. & 5.87 br s \\
\hline 2 & 72.8 & 6.44 br s & 72.7 & 6.32 br s & 73.0 & 6.36 br s \\
\hline 3 & 79.7 & $4.93 \mathrm{dd}(9.0,3.0)$ & 80.0 & $4.84 \mathrm{dd}(9.5,3.5)$ & 79.9 & $4.83 \mathrm{dd}(8.5,3.0)$ \\
\hline 4 & 78.2 & $4.26 \mathrm{dd}(9.0,9.0)$ & 78.3 & $4.17 \mathrm{dd}(9.5,9.5)$ & 78.4 & $4.16 \mathrm{dd}(8.5,8.5)$ \\
\hline 5 & 68.3 & $4.62 *$ & 68.4 & $4.44 *$ & 68.5 & $4.50 *$ \\
\hline 6 & 18.8 & $1.76 \mathrm{~d}(5.5)$ & 19.1 & $1.69 \mathrm{~d}(6.5)$ & 19.0 & $1.67 \mathrm{~d}(5.5)$ \\
\hline Rha"-1 & 103.2 & $6.41 \mathrm{br} \mathrm{s}$ & 99.8 & $5.96 \mathrm{br} \mathrm{s}$ & 103. & $6.31 \mathrm{br} \mathrm{s}$ \\
\hline 2 & 69.7 & 5.38 br s & 74.1 & 6.29 br s & 69.9 & 5.29 br s \\
\hline 3 & 73.1 & $6.11 \mathrm{dd}(3.0,10.0)$ & 68.2 & $4.79 \mathrm{dd}(3.5,10.0)$ & 73.3 & $6.02 \mathrm{dd}(3.0,10.0)$ \\
\hline 4 & 71.5 & $6.19 \mathrm{t}(10.0)$ & 74.7 & $5.82 \mathrm{t}(10.0)$ & 71.7 & $6.11 \mathrm{t}(10.0)$ \\
\hline 5 & 67.9 & $4.56 *$ & 68.2 & $4.49 \mathrm{dd}(10.0,6.5)$ & 68.2 & $4.44 *$ \\
\hline 6 & 17.7 & $1.55 \mathrm{~d}(6.0)$ & 18.0 & $1.54 \mathrm{~d}(6.5)$ & 17.9 & $1.45 \mathrm{~d}(6.5)$ \\
\hline Glu'-1 & 105.3 & $5.24 \mathrm{~d}(7.2)$ & 105.0 & $4.92 \mathrm{~d}(7.5)$ & 105. & $5.14 \mathrm{~d}(7.5)$ \\
\hline 2 & 75.0 & $4.08 *$ & 75.0 & $3.89 *$ & 75.2 & $3.94 *$ \\
\hline 3 & 78.7 & $4.19^{*}$ & 78.4 & $4.19^{*}$ & 79.0 & $4.07 *$ \\
\hline 4 & 71.3 & $4.05^{*}$ & 71.4 & $4.14 *$ & 71.5 & $3.97 *$ \\
\hline 5 & 77.9 & $3.92 *$ & 78.3 & $3.82 *$ & 78.1 & $3.82 *$ \\
\hline 6 & 62.7 & $\begin{array}{l}4.54 * \\
4.21 *\end{array}$ & 63.0 & $\begin{array}{l}4.40 * \\
4.10 *\end{array}$ & 63.0 & $\begin{array}{l}4.44 * \\
4.11 *\end{array}$ \\
\hline $\mathrm{Ag}-1$ & 173.0 & & 173.4 & & 173. & \\
\hline 2 & 34.0 & $2.46 \mathrm{~m}, 2.39 \mathrm{~m}$ & 34.3 & $2.47 \mathrm{~m}, 2.33 \mathrm{~m}$ & 34.3 & $2.37 \mathrm{~m}, 2.30 \mathrm{~m}$ \\
\hline 11 & 82.5 & $4.00 *$ & 82.8 & $3.99 *$ & 82.7 & $3.90 *$ \\
\hline 16 & 14.1 & $0.83 \mathrm{t}(7.5)$ & 14.3 & $0.86 \mathrm{t}(7.0)$ & 14.3 & $0.83 \mathrm{t}(7.5)$ \\
\hline Cna-1 & 166.2 & & 167.0 & & 166. & \\
\hline 2 & 118.3 & $6.70 \mathrm{~d}(16.0)$ & 118.7 & $6.37 \mathrm{~d}(16.0)$ & 118. & $6.60 \mathrm{~d}(16.0)$ \\
\hline 3 & 145.3 & $7.97 \mathrm{~d}(16.0)$ & 145.2 & $7.66 \mathrm{~d}(16.0)$ & 145. & $7.87 \mathrm{~d}(16.0)$ \\
\hline $1^{\prime}$ & 134.6 & & 134.6 & & 134. & \\
\hline $2^{\prime}$ and $6^{\prime}$ & 128.3 & $7.56 \mathrm{~m}$ & 128.5 & $7.26 \mathrm{~m}$ & 128. & $7.46 \mathrm{~m}$ \\
\hline $3^{\prime}$ and $5^{\prime}$ & 129.0 & $7.45 \mathrm{~m}$ & 129.0 & $7.17 \mathrm{~m}$ & 129. & $7.35 \mathrm{~m}$ \\
\hline $4^{\prime}$ & 130.5 & $7.45 \mathrm{~m}$ & 130.5 & $7.17 \mathrm{~m}$ & 130. & $7.35 \mathrm{~m}$ \\
\hline Mba-1 & 175.8 & & 176.4 & & 176. & \\
\hline 2 & 41.3 & $2.59 \mathrm{~m}$ & 41.2 & $2.53 \mathrm{~m}$ & 41.6 & $2.49 \mathrm{~m}$ \\
\hline
\end{tabular}




\begin{tabular}{clllllc}
\hline $2-\mathrm{CH}_{3}$ & 16.7 & $1.25 \mathrm{~d}(7.0)$ & 17.0 & $1.22 \mathrm{~d}(7.0)$ & 17.0 & $1.15 \mathrm{~d}(7.0)$ \\
4 & 11.6 & $0.95 \mathrm{t}(7.0)$ & 11.7 & $0.92 \mathrm{t}(7.0)$ & 11.8 & $0.87 \mathrm{t}(7.0)$ \\
Deca-1 & 173.4 & & & & & \\
2 & 34.2 & $2.43 \mathrm{~m}$ & & & & \\
12 & 14.1 & $0.93 \mathrm{t}(5.5)$ & & & 173. & \\
Dodeca-1 & & & 173.9 & & 34.4 & $2.35 \mathrm{~m}$ \\
2 & & & 34.4 & $2.37 \mathrm{~m}$ & 1.8 .3 & $0.83 \mathrm{t}(7.5)$ \\
\hline 12 & & & 14.3 & $0.86 \mathrm{t}(7.0)$ & 14.3 \\
\hline
\end{tabular}

Chemical shifts $(\delta)$ are in ppm relative to TMS. The spin coupling $(J)$ is given in parentheses $(\mathrm{Hz})$. Chemical shifts marked with an asterisk (*) indicate overlapped signals. Spin-coupled patterns are designated as follows: br $\mathrm{s}=$ broad singlet, $\mathrm{d}=$ doublet, $\mathrm{t}=$ triplet, $\mathrm{m}=$ multiplet. Abbreviations: $\mathrm{Glc}=$ glucose $; \mathrm{Rha}=$ rhamnose $\mathrm{Ag}=11$ - hydroxyhexadecanoyl; $\mathrm{Mba}=2 S$ methylbutanoyl $;$ Cna $=$ trans-cinnamoyl $;$ Deca $=n$-decanoyl $;$ Dodeca $=n$-dodecanoyl .

Table S2 $\alpha$-Glucosidase inhibition of compounds 1-3 and acarbose

\begin{tabular}{cc}
\hline Compound & $\begin{array}{c}\boldsymbol{\alpha} \text {-Glucosidase Inhibition Contstant } \\
\left(\mathbf{I C}_{\mathbf{5 0}}\right)[\boldsymbol{\mu M}]\end{array}$ \\
\hline $\mathbf{1}$ & $188.6 \pm 5.2$ \\
$\mathbf{2}$ & $157.8 \pm 4.6$ \\
$\mathbf{3}$ & $174.4 \pm 3.9$ \\
acarbose & $388.0 \pm 8.5$ \\
\hline
\end{tabular}

${ }^{\mathrm{a}} \mathrm{IC}_{50}$ is defined as the concentration that resulted in a $50 \% \alpha$-glucosidase inhibition and the results are means \pm standard deviation of three independent replicates; ${ }^{b}$ Positive control substance.

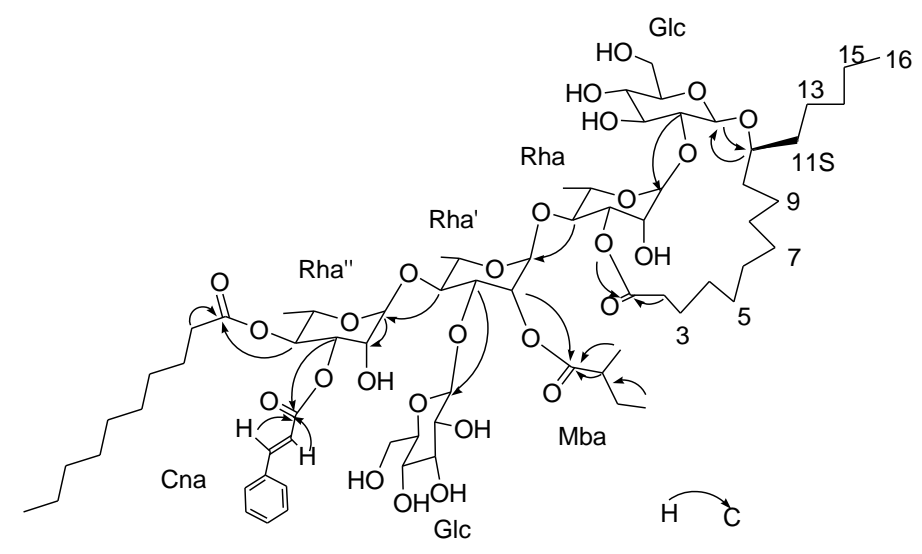

Figure S1. Key HMBCs from H to C for Acutacoside C (1) 
The identification procedures of organic acids, sugars, and aglycone:

Compounds 1-3 (7 mg each) in 5\% KOH (3 mL) were refluxed at $90{ }^{\circ} \mathrm{C}$ for $2 \mathrm{~h}$, respectively. The reaction mixture was acidified to $\mathrm{pH} 4.0$ with $2 \mathrm{~mol} / \mathrm{L} \mathrm{HCl}$ and extracted with hexane $(3 \mathrm{~mL} \times 2)$ and $n-\mathrm{BuOH}(3 \mathrm{~mL} \times 2)$. The organic layer was washed with $\mathrm{H}_{2} \mathrm{O}$, dried over anhydrous $\mathrm{Na}_{2} \mathrm{SO}_{4}$, then methylated following. The hexane extract, was combined with $0.1 \mathrm{~mL} 0.5 \mathrm{M} \mathrm{CH}_{3} \mathrm{ONa}$ solution, then shaken for 5 min at room temperature, before adding $5 \mu \mathrm{L} \mathrm{CH}_{3} \mathrm{COOH}$ and $1 \mathrm{~g}$ anhydrous $\mathrm{CaCl}_{2}$ powder, heating for $1 \mathrm{~h}$, followed by centrifugation for 2-3 $\mathrm{min}$ at 2000-3000 rpm. $\mathrm{min}^{-1}$. The supernatant was analyzed by GC-MS on a TRACE GC ULTRA DSQ II intrument under the following conditions: $30 \mathrm{~m} \times 0.25 \mathrm{~mm} \times 0.25 \mu \mathrm{m}$, TG-5MS (Thermo) column; He, $0.8 \mathrm{~mL} / \mathrm{min} ; 40{ }^{\circ} \mathrm{C}, 3 \mathrm{~min} ; 50-310{ }^{\circ} \mathrm{C}, \Delta 0{ }^{\circ} \mathrm{C} / \mathrm{min}, 70 \mathrm{eV}$. 2-Methylbutyric acid methyl ester $\left(t_{\mathrm{R}} 4.39 \mathrm{~min}\right) \mathrm{m} / \mathrm{z}[\mathrm{M}+\mathrm{H}]^{+} 117$ (5), 101 (23), 88 (96), 57 (100), 41 (55), 29 (45), 27 (19), and trans-cinnamic acid methyl ester $\left(t_{\mathrm{R}}\right.$ $13.29 \mathrm{~min}) \mathrm{m} / \mathrm{z}[\mathrm{M}]^{+} \mathrm{m} / \mathrm{z} 162$ (40), 131 (100), 103 (66), 77 (32), from 1-3 was identified. $n$-decanoic acid methyl ester ( $\left.t_{\mathrm{R}} 12.37 \mathrm{~min}\right): \mathrm{m} / z 172[\mathrm{M}]^{+}$(4), 155 (5), 143 (30), 129 (5), 87 (59), 74 (100), 55 (18) from 1 was identified. $n$-dodecanoyl acid methyl ester ( $\left.\mathrm{t}_{\mathrm{R}} 15.17 \mathrm{~min}\right) \mathrm{m} / \mathrm{z}[\mathrm{M}]^{+} 200$ (1), 172 (1), 168 (10), 157 (15), 143(18), 129 (7), 87 (64), 74 (100), 55 (25), 43 (20), 41 (18) from 2-3 was identified. The 2-methylbutanoic acid as proved to be $S$ configuration by comparing the specific rotation with that of authentic $2 S$-methylbutanoic acid (Yin, Y.Q., Wang, J.S., Luo, J.G., Kong, L.Y., 2009). Acidic hydrolysis of operculinic acid B liberated the aglycone, 11-hydroxyhexadecanoic acid, which was identifidey $S$-configuration (Yin, Y.Q., et al., 2008) and the monosaccharides mixture was derivatized and detected with GC-MS by comparison with those of authentic samples to improve as D-fucose, L-rhamnose and D-glucose (Luo, J.G., Ma, L., Kong, L.Y., 2008). 


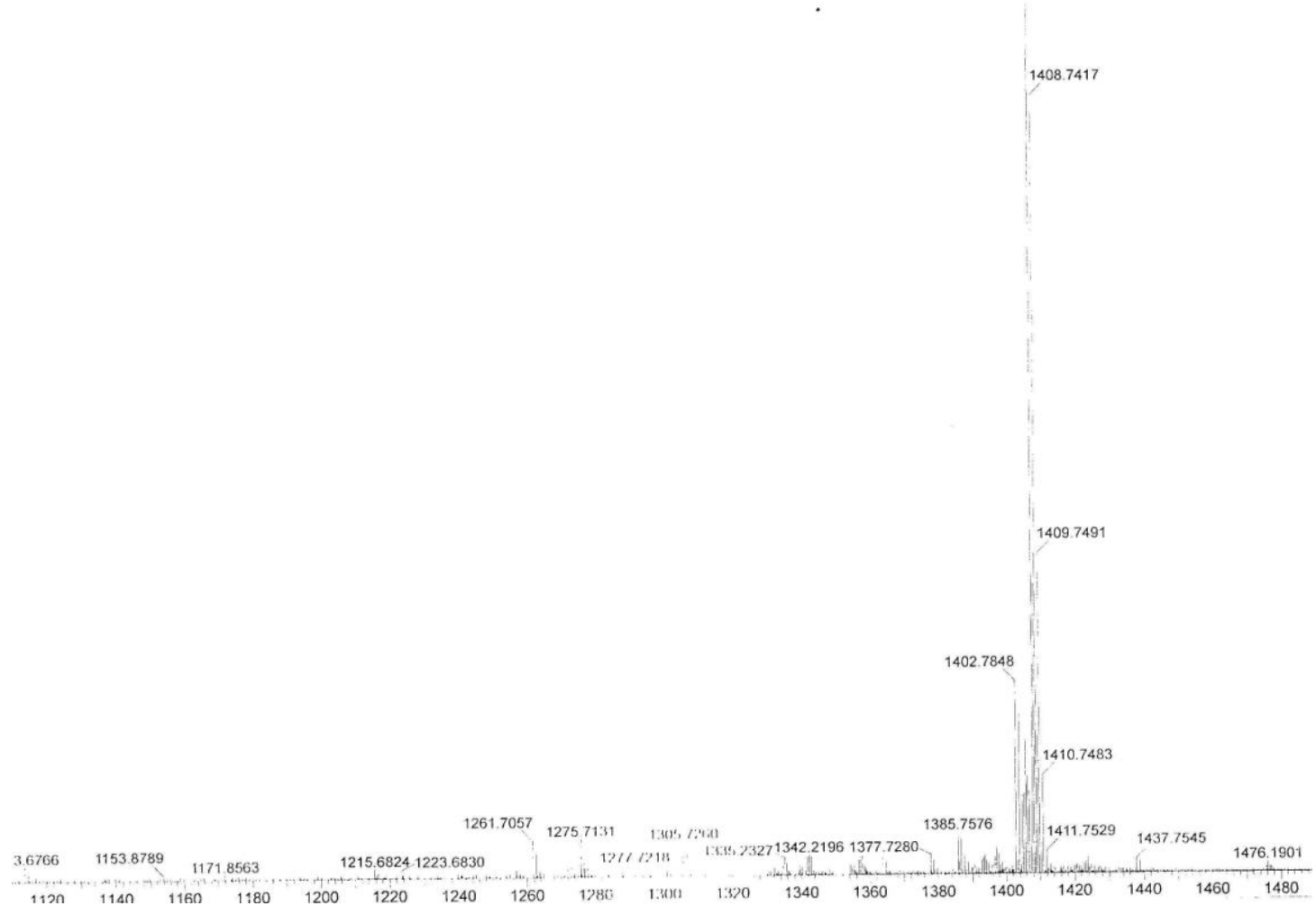

Figure S2. The HR-TOF-MS spectrum of compound 1

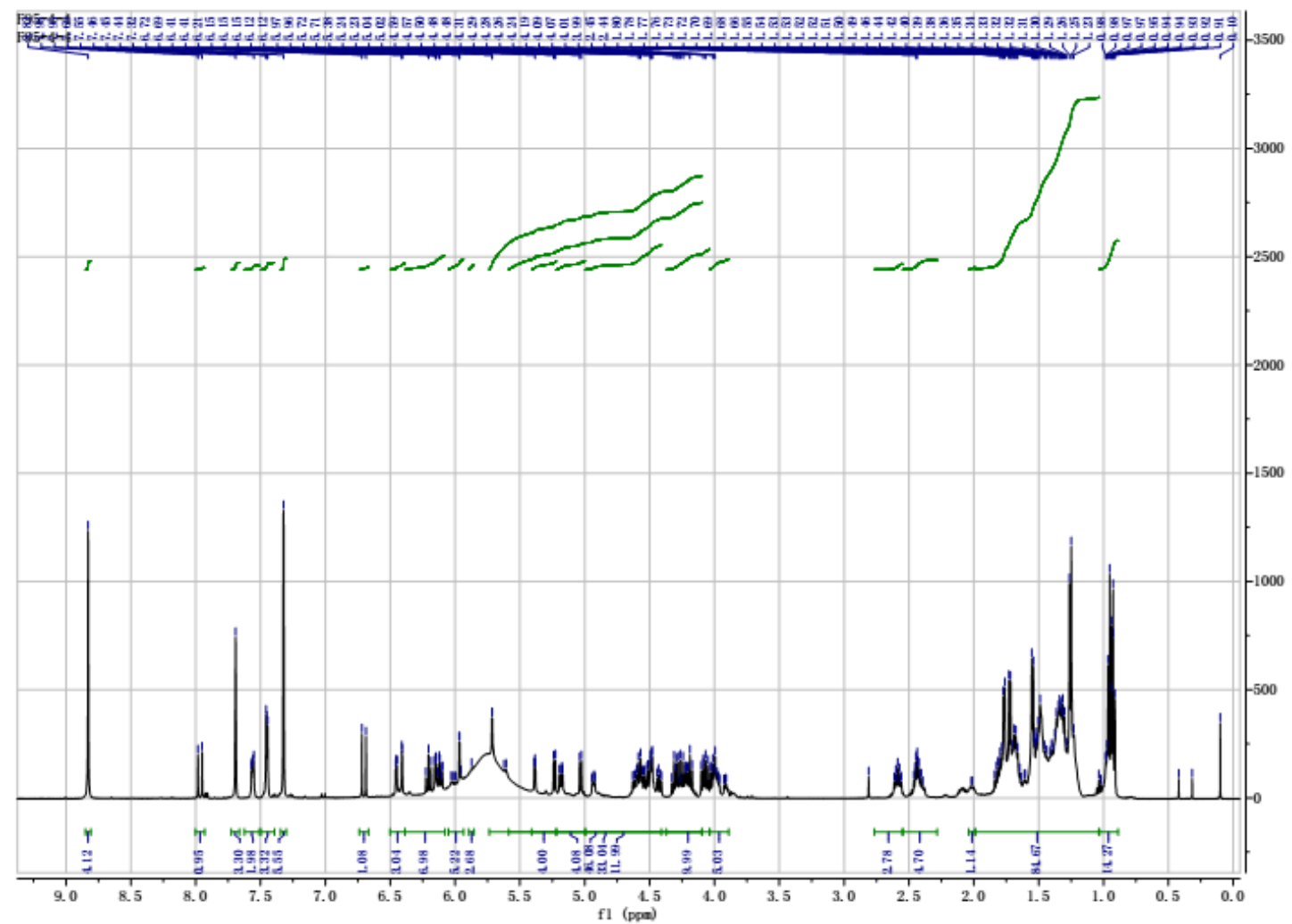

Figure S3. The ${ }^{1} \mathrm{H}-\mathrm{NMR}$ spectrum of compound $\mathbf{1}$ 


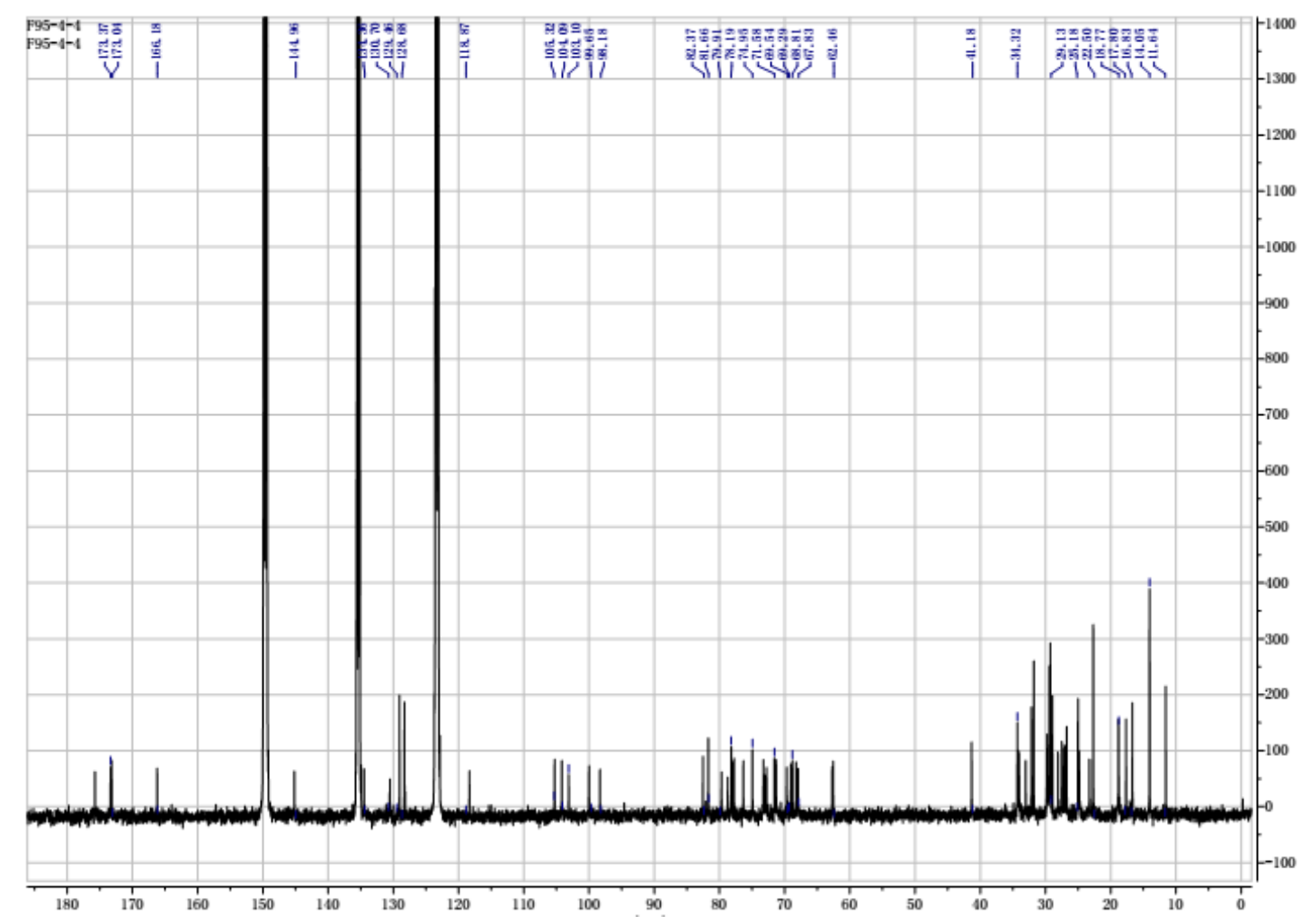

Figure S4. The ${ }^{13} \mathrm{C}$-NMR spectrum of compound $\mathbf{1}$

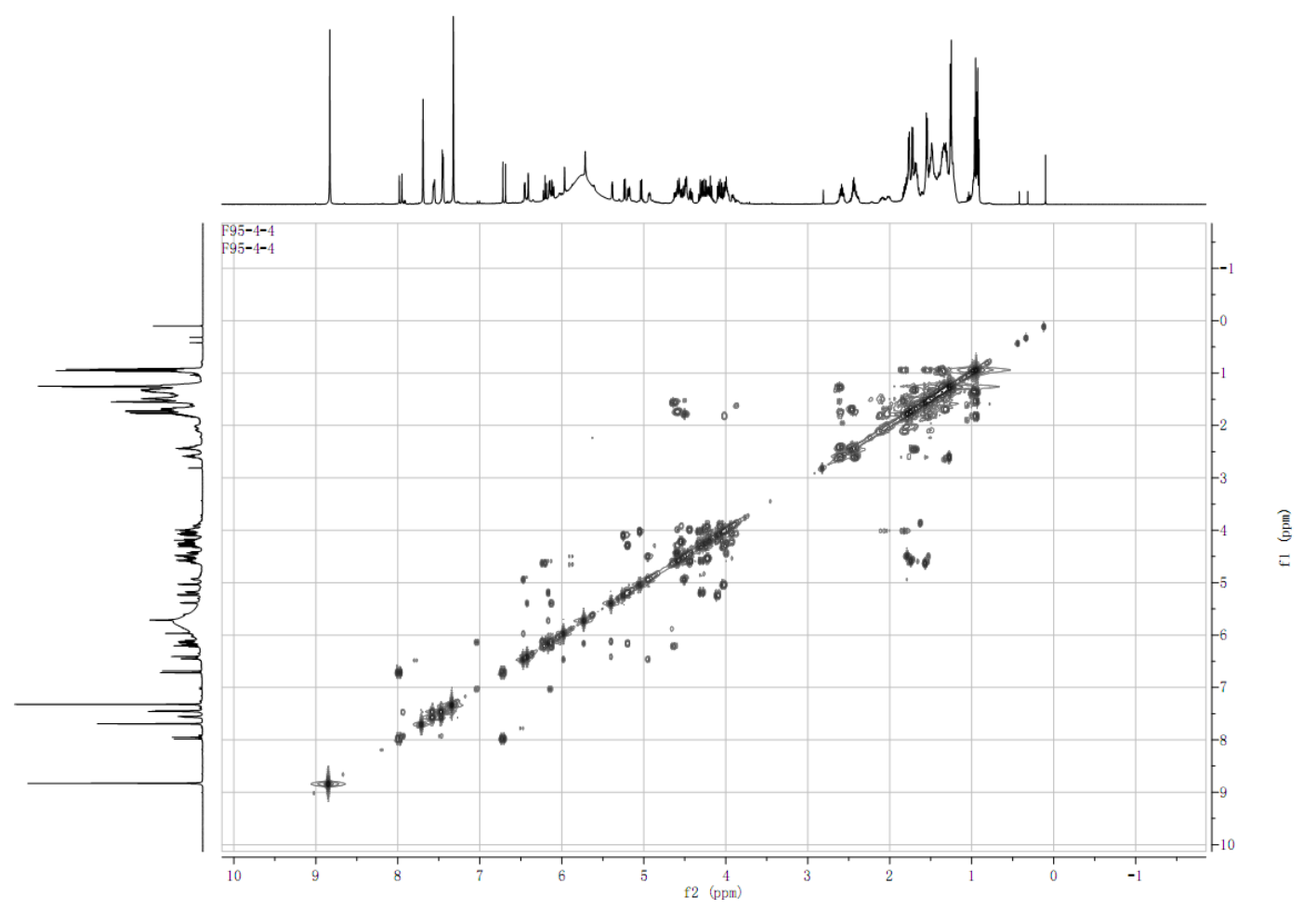


Figure S5. The TOCSY spectrum of compound $\mathbf{1}$

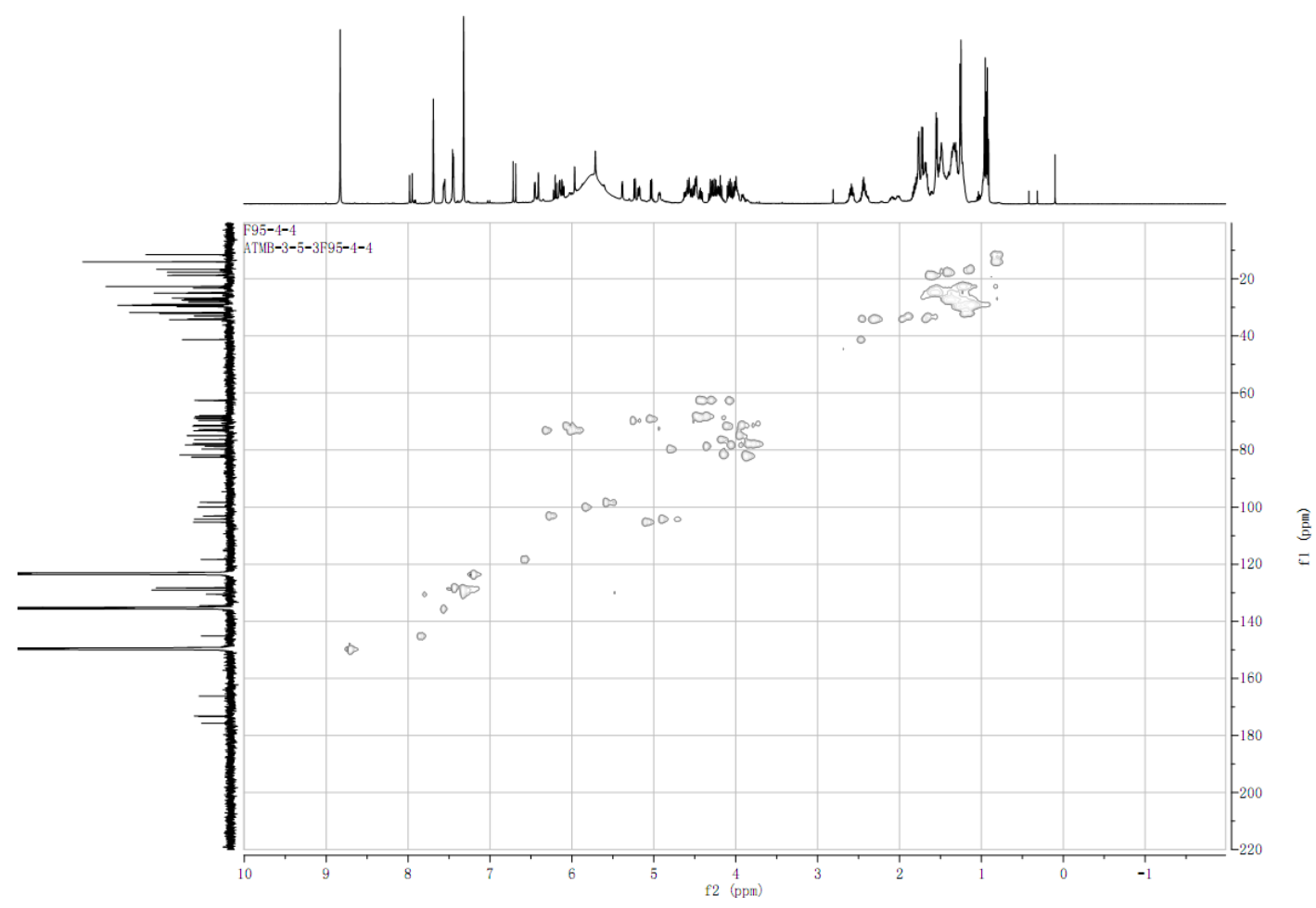

Figure S6. The HSQC spectrum of compound $\mathbf{1}$

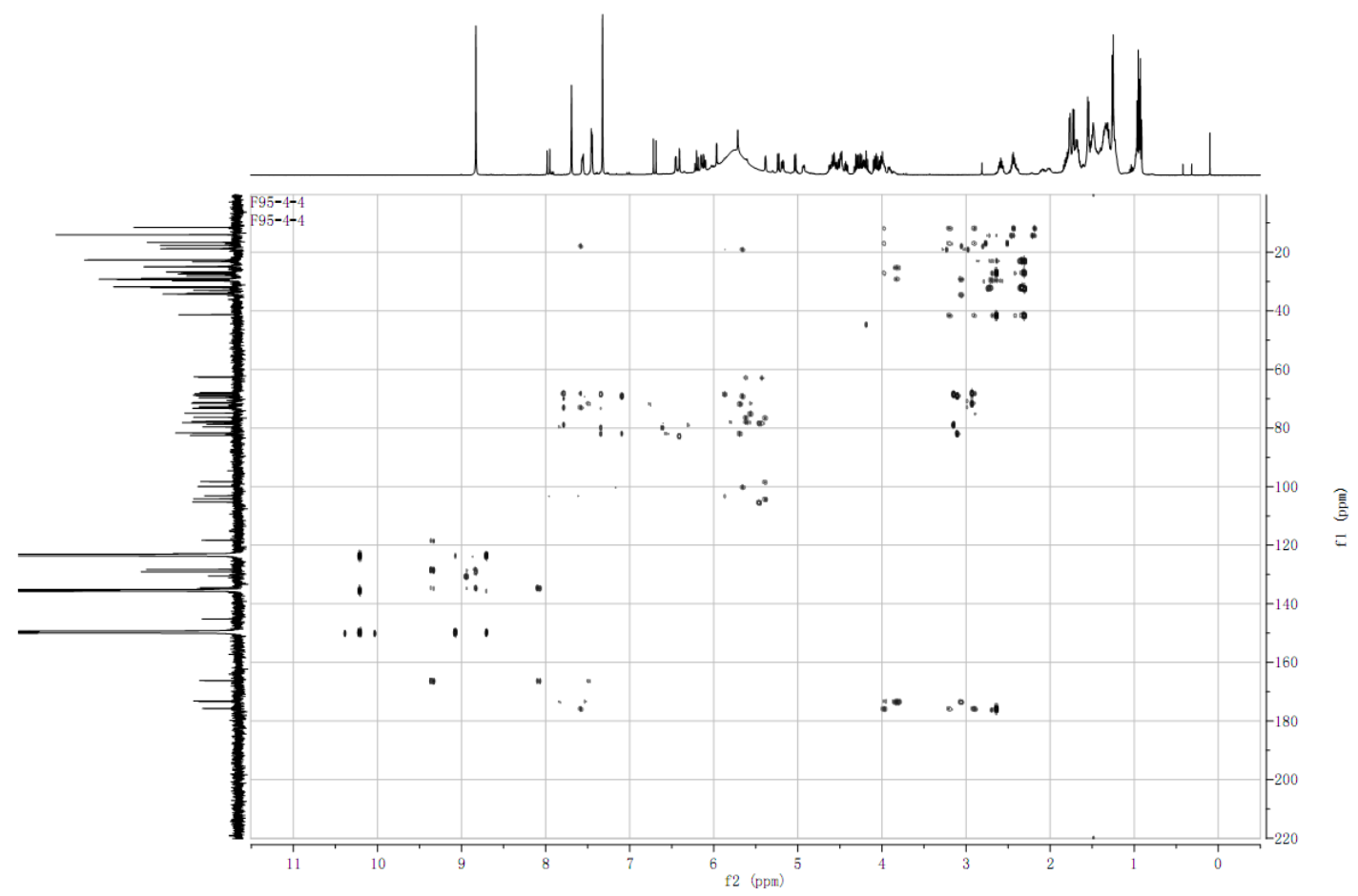

Figure S7. The HMBC spectrum of compound 1 


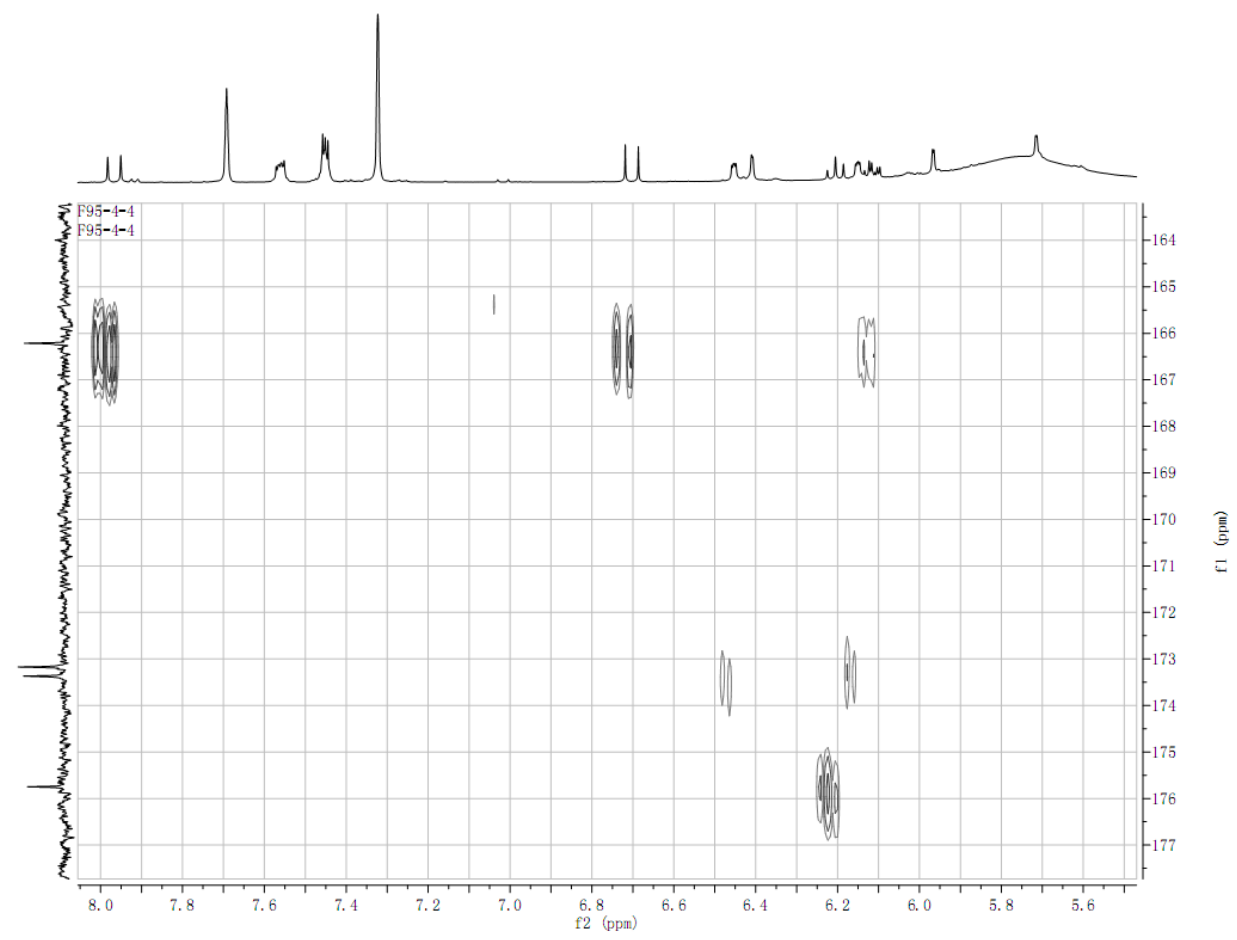

Figure S8. The enlarged HMBC spectrum of compound $\mathbf{1}$

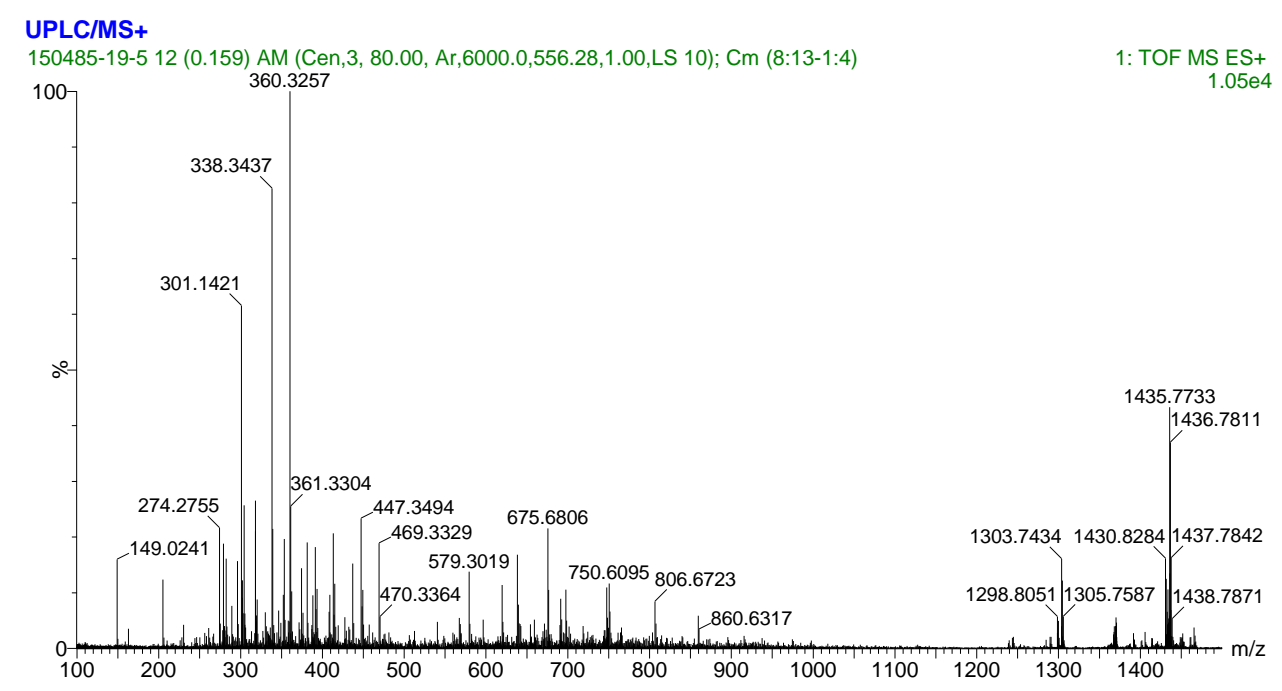

Figure S9. The HR-TOF-MS spectrum of compound 2 


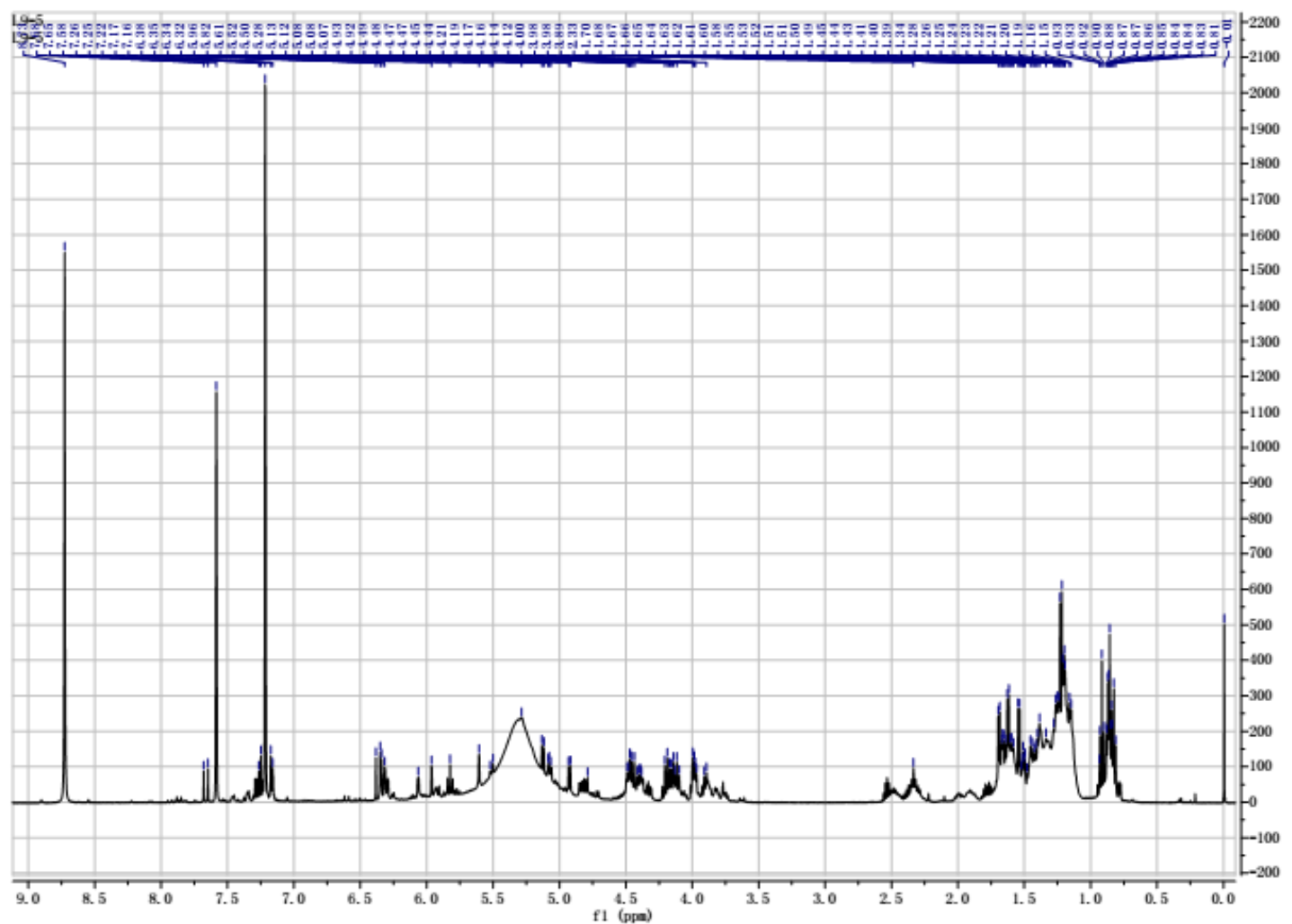

Figure S10. The ${ }^{1} \mathrm{H}-\mathrm{NMR}$ spectrum of compound $\mathbf{2}$

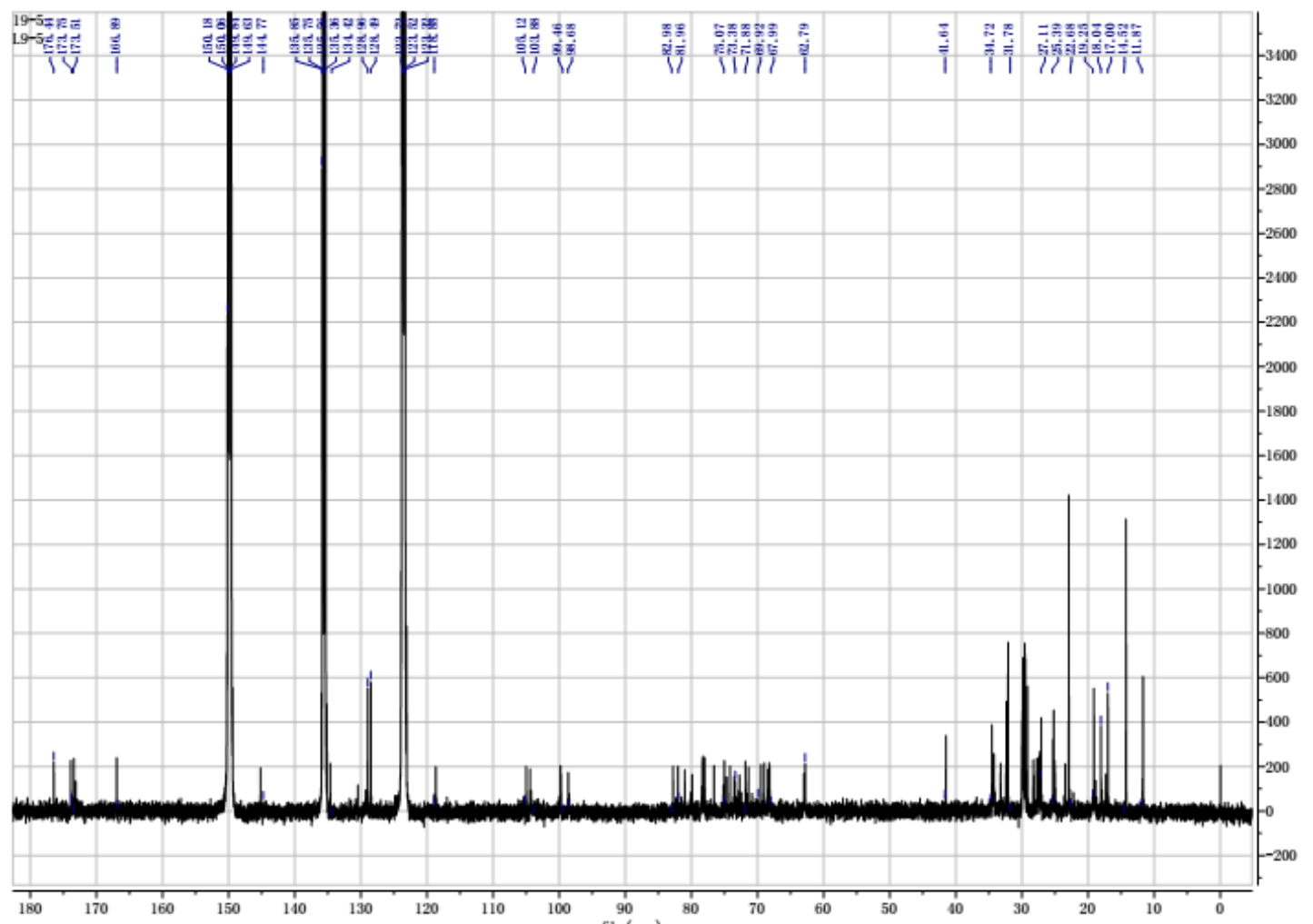

Figure S11. The ${ }^{13}$ C-NMR spectrum of compound 2 


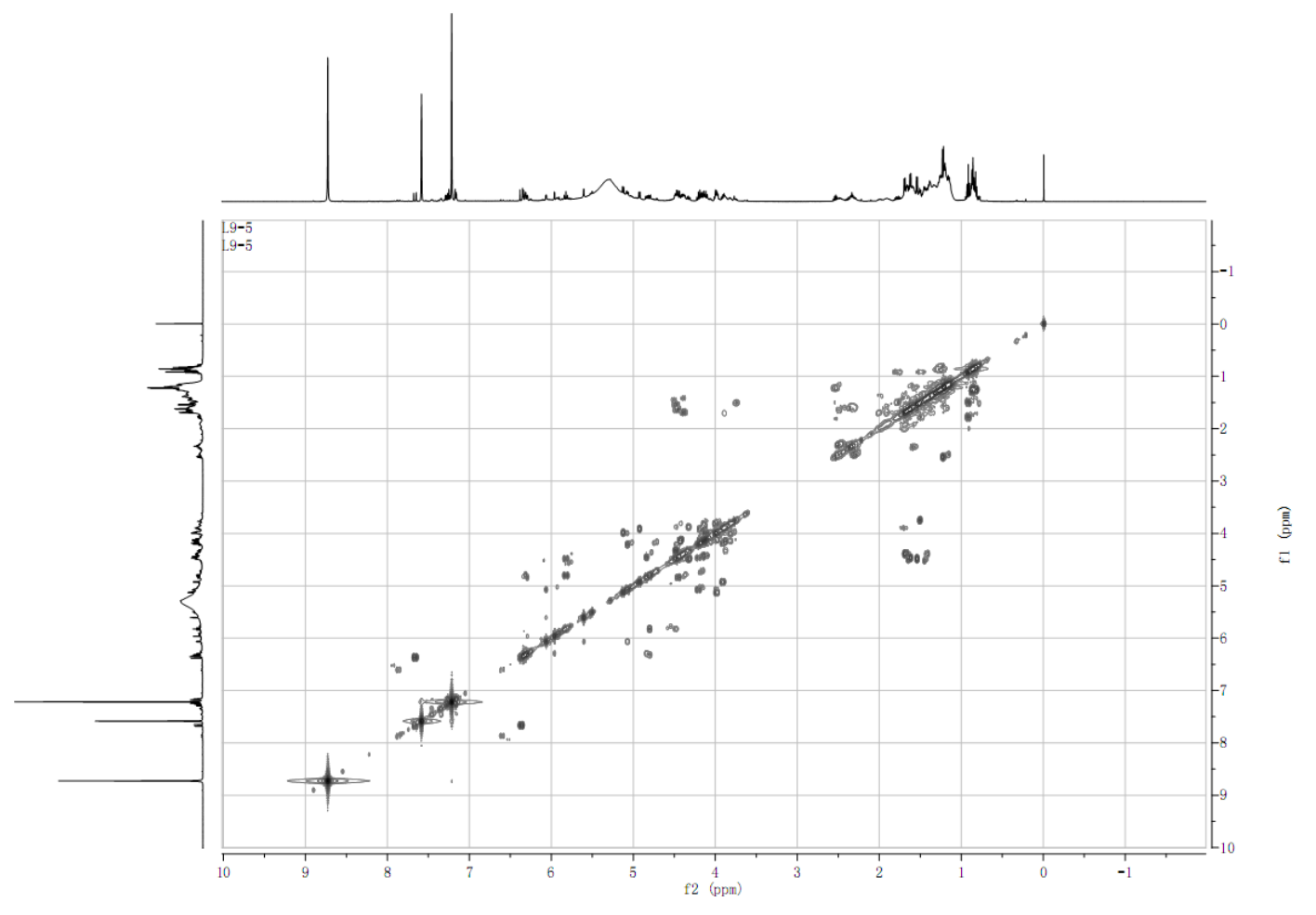

Figure S12. The TOCSY spectrum of compound 2

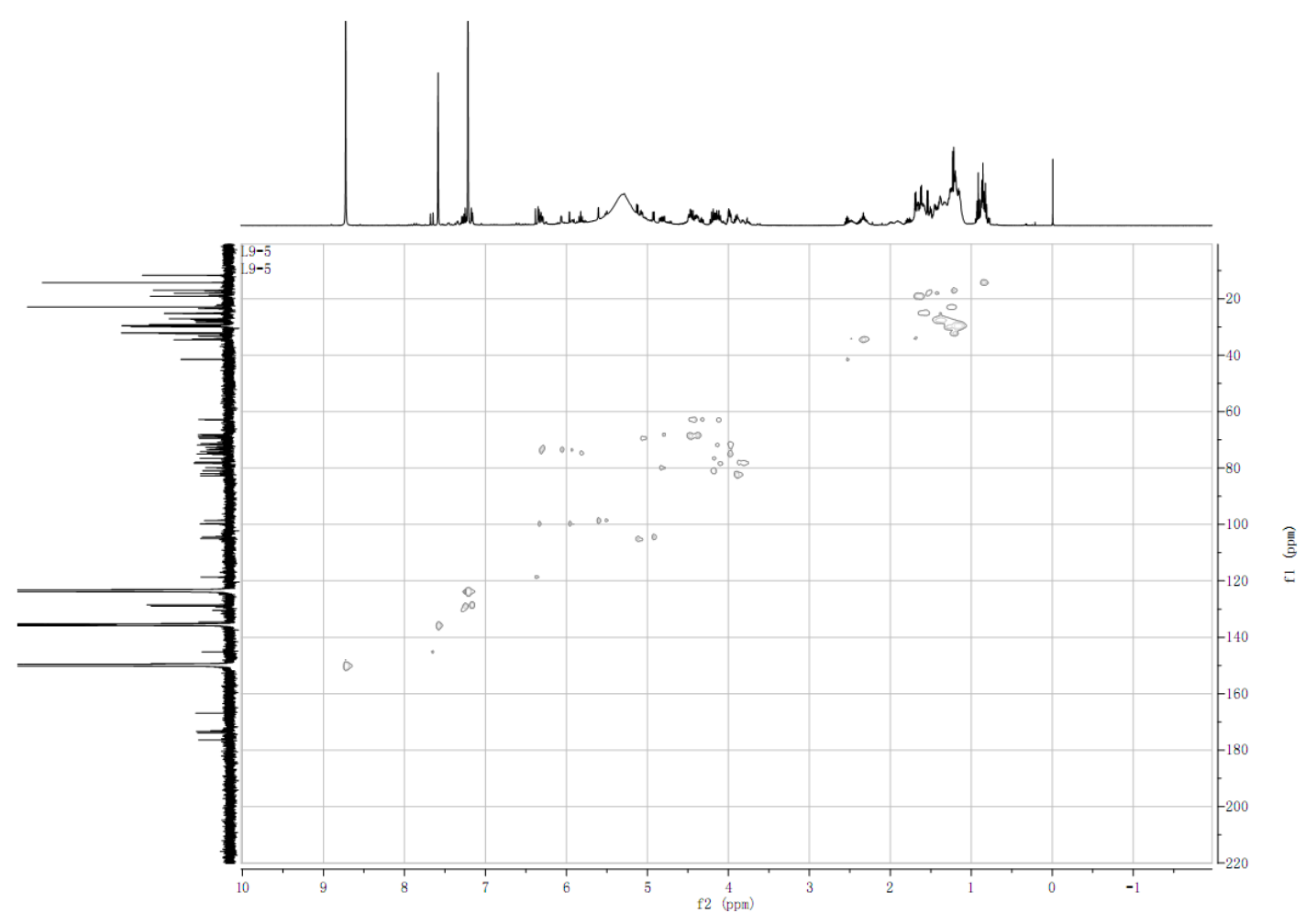

Figure S13. The HSQC spectrum of compound 2 


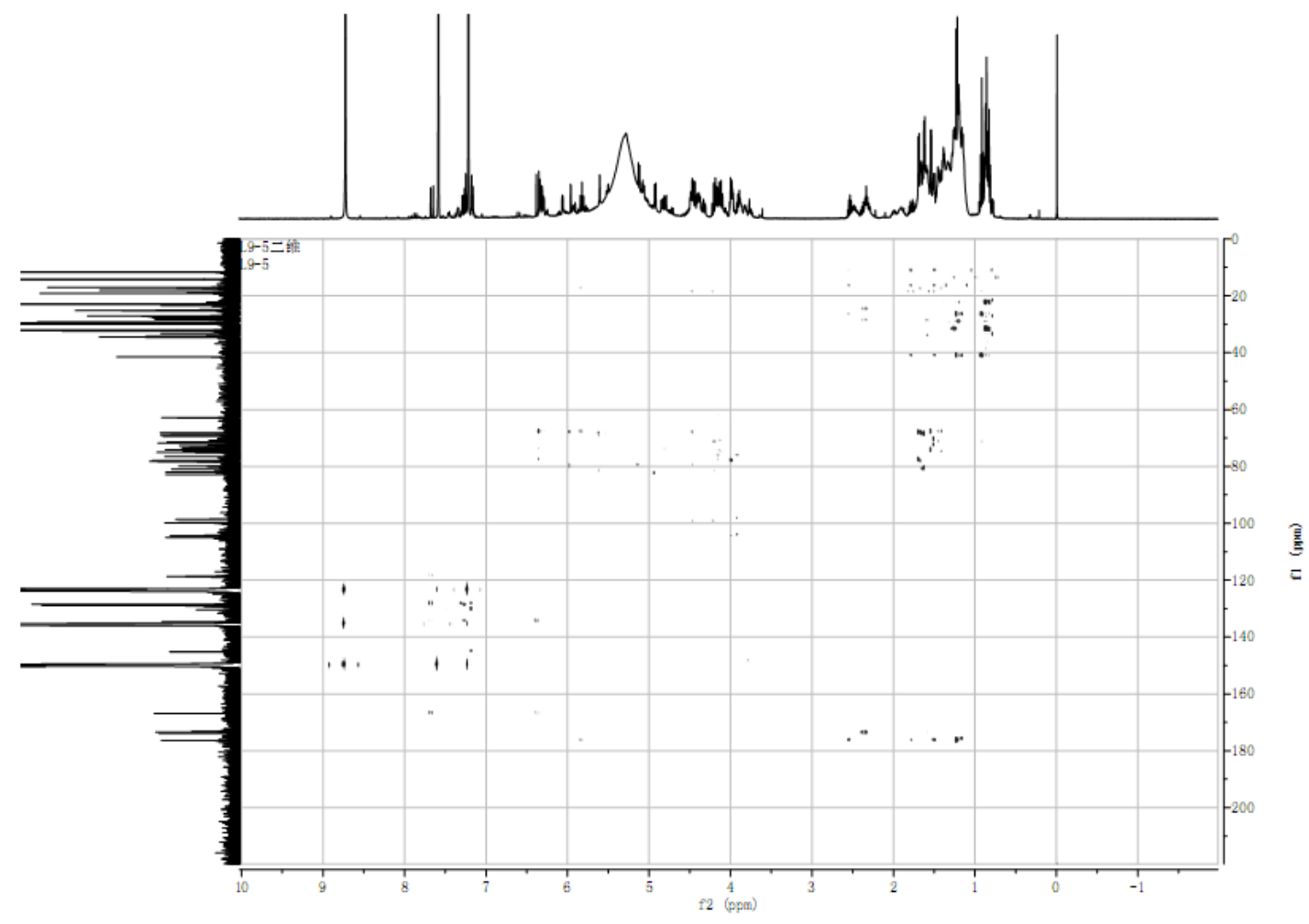

Figure S14. The HMBC spectrum of compound 2

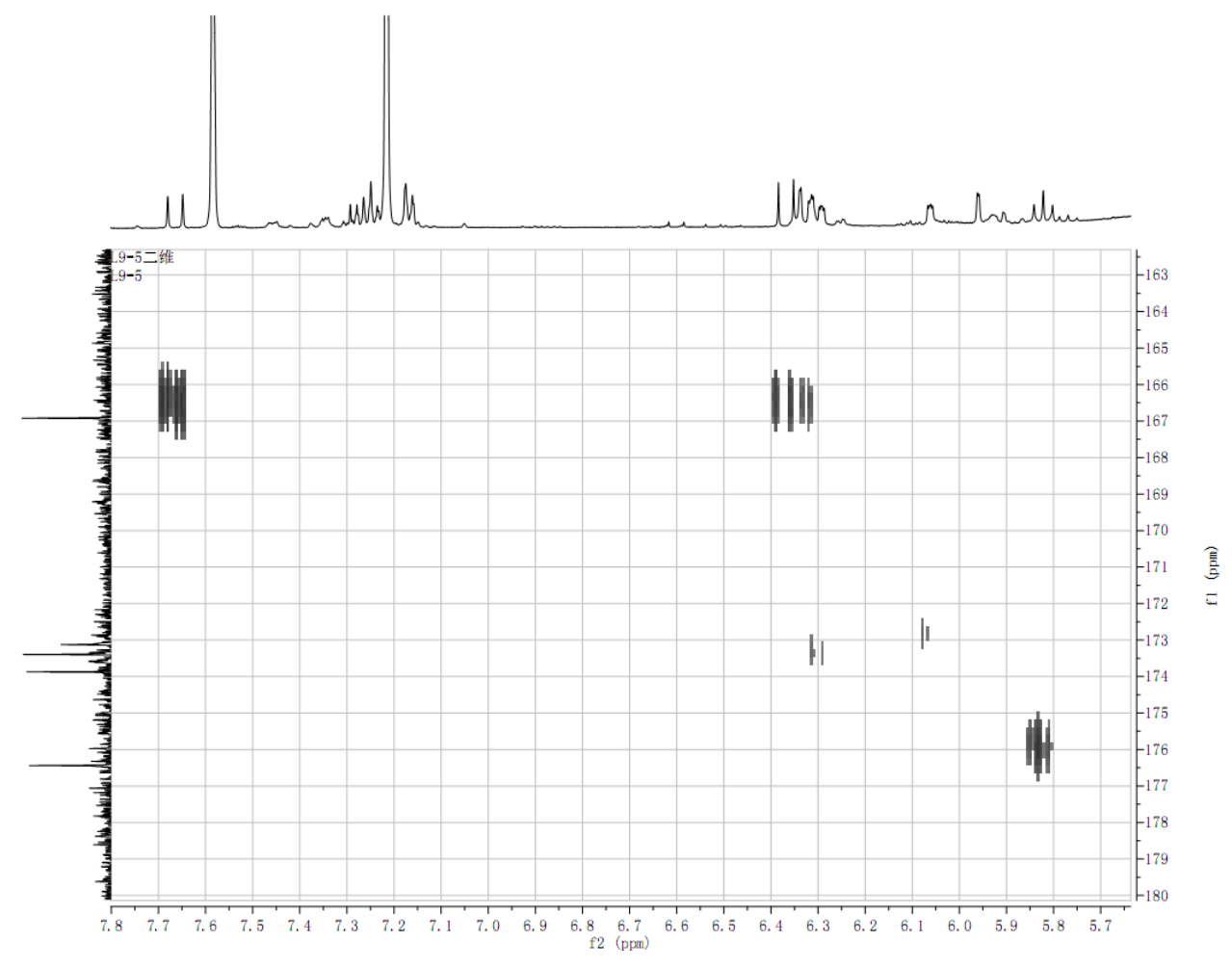

Figure S15. The enlarged HMBC spectrum of compound 2 


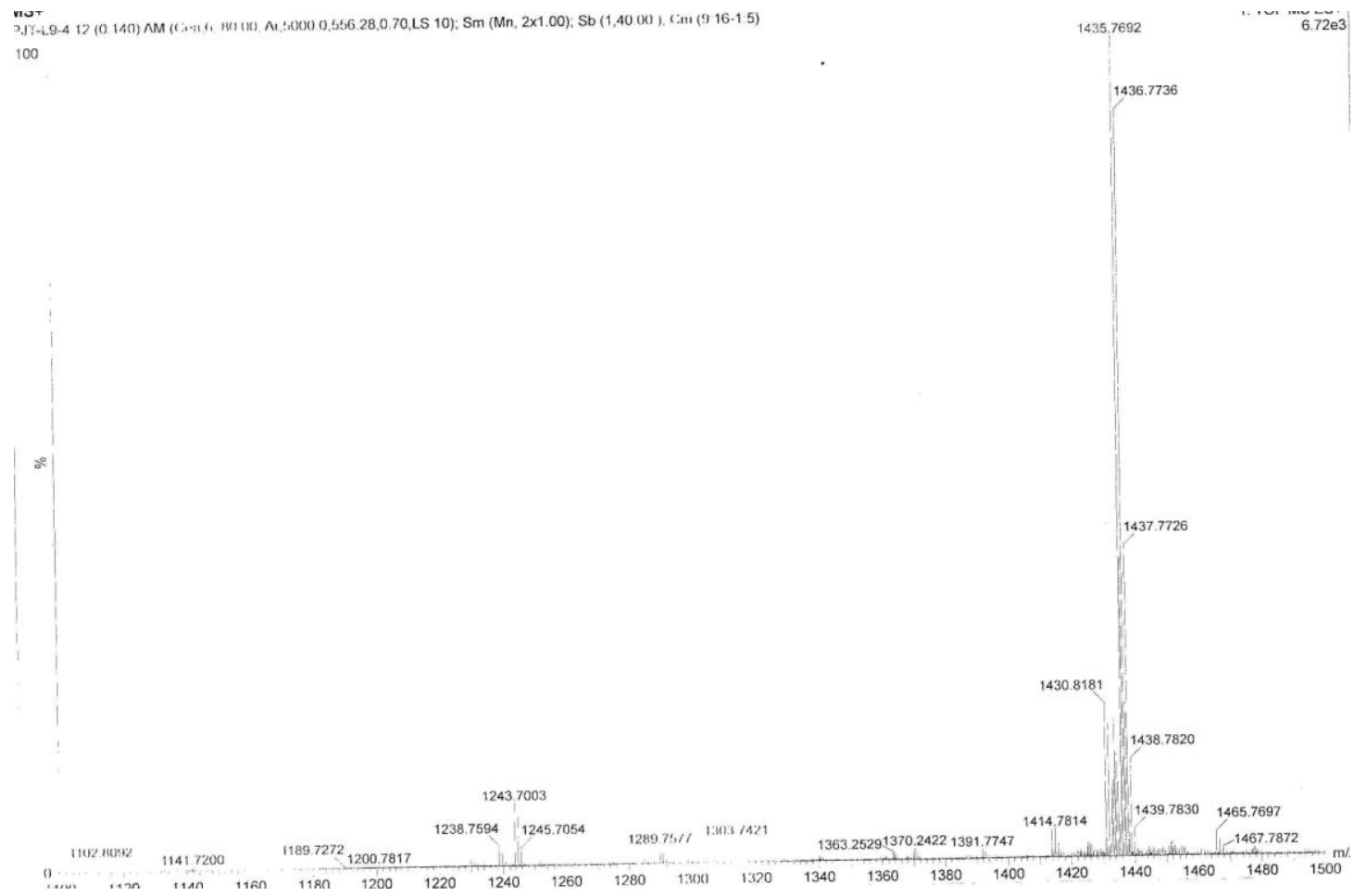

Figure S16. The HR-TOF-MS spectrum of compound 3

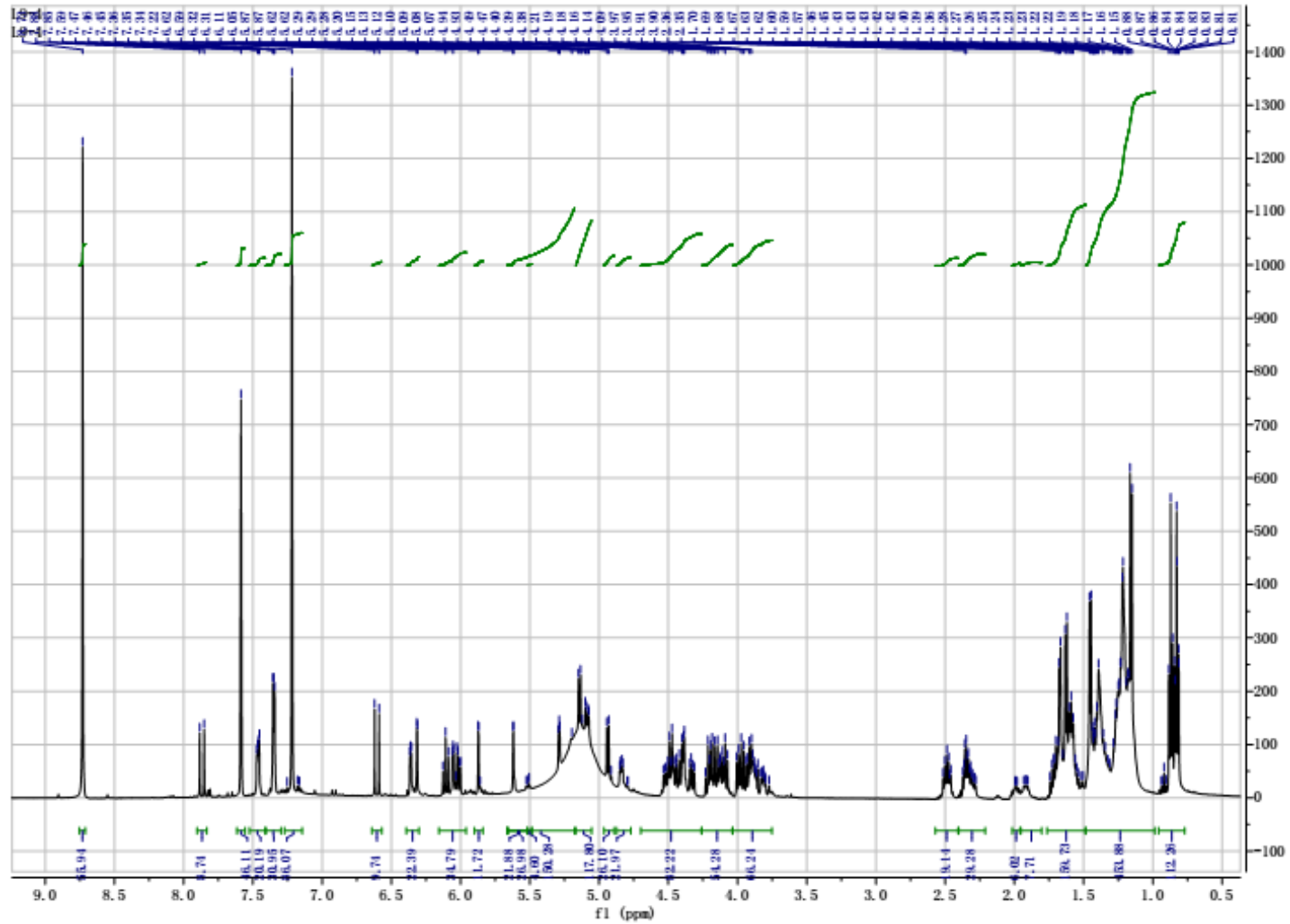

Figure S17. The ${ }^{1} \mathrm{H}-\mathrm{NMR}$ spectrum of compound $\mathbf{3}$ 


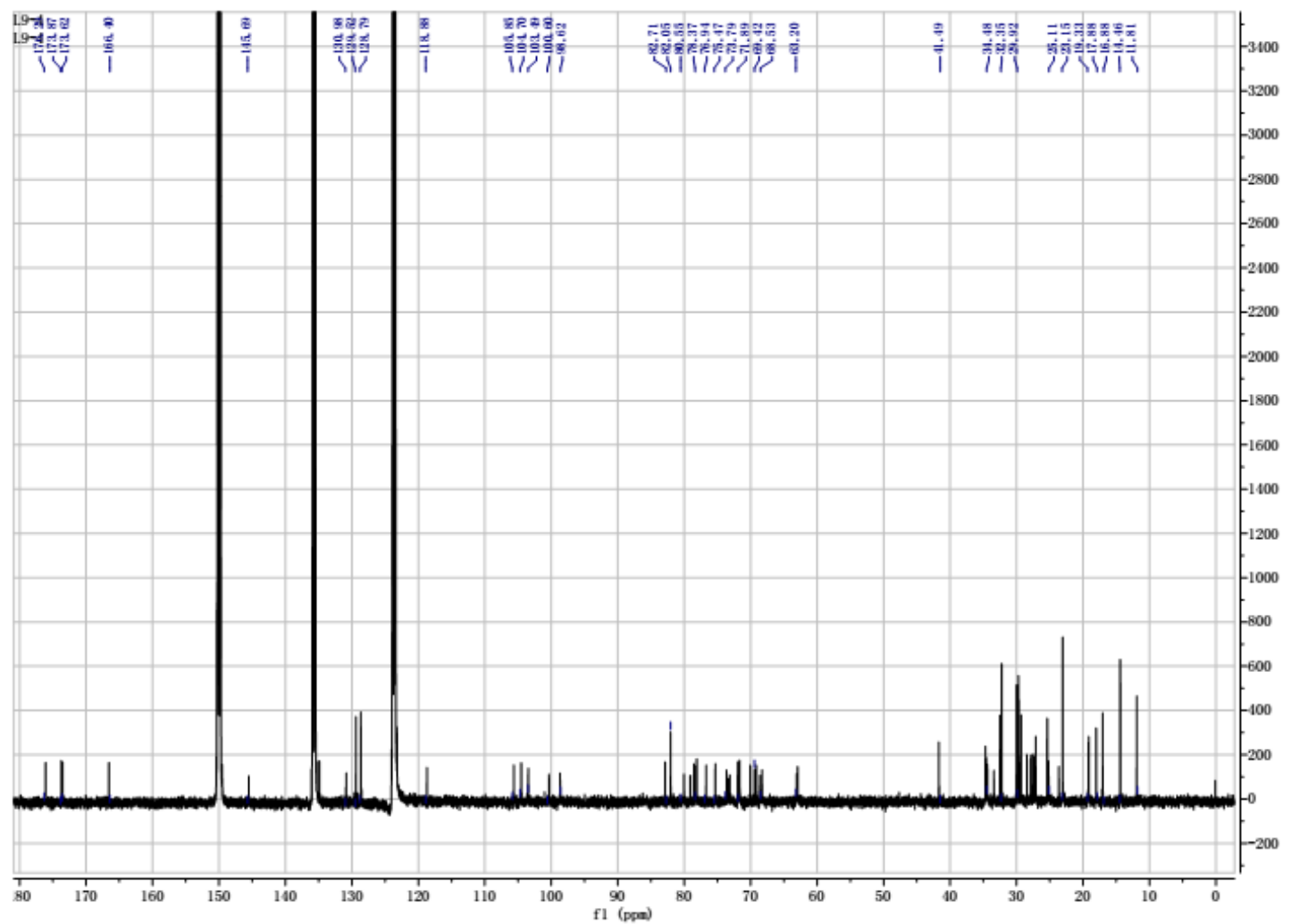

Figure S18. The ${ }^{13} \mathrm{C}-\mathrm{NMR}$ spectrum of compound $\mathbf{3}$

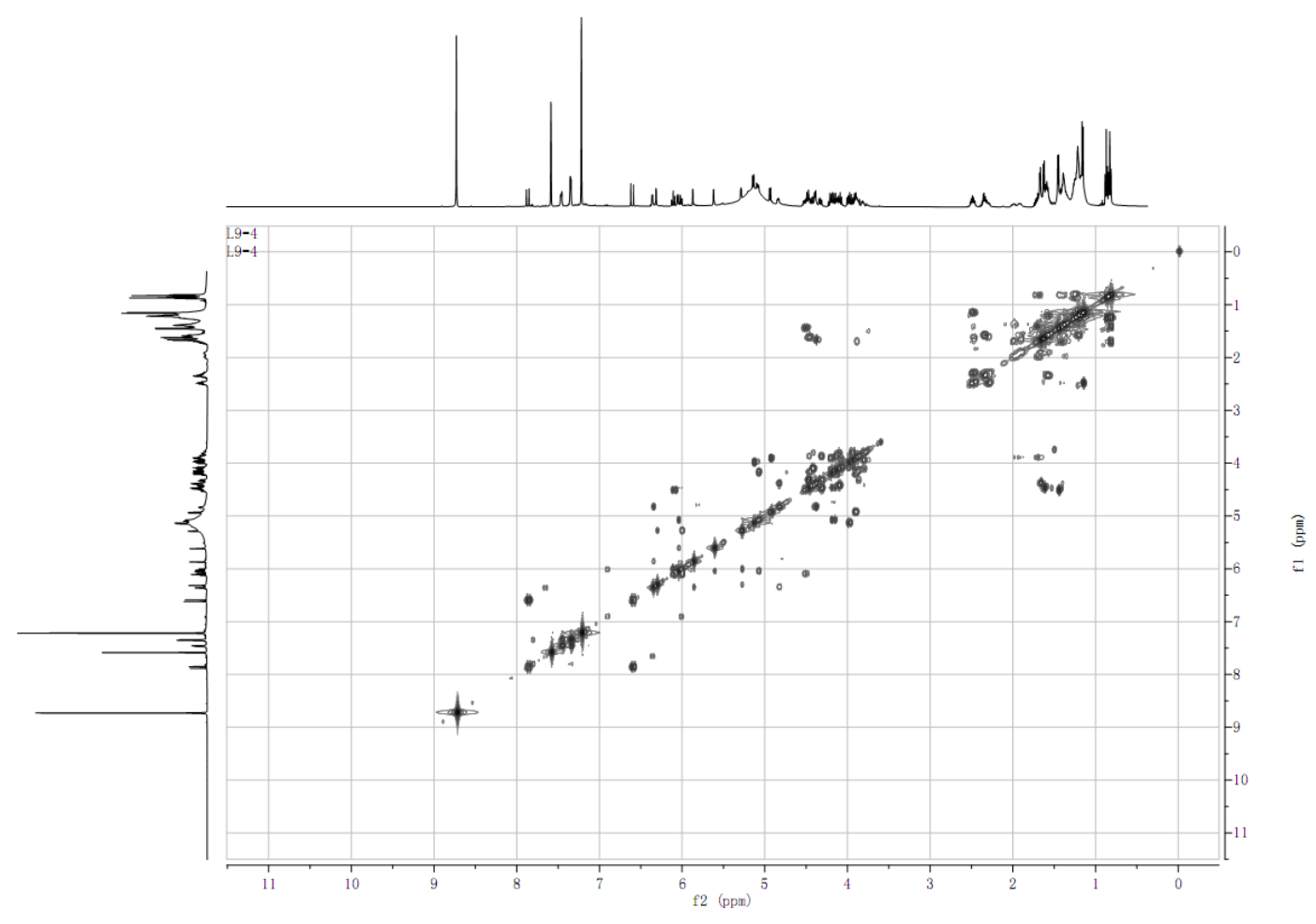

Figure S19. The TOCSY spectrum of compound $\mathbf{3}$ 


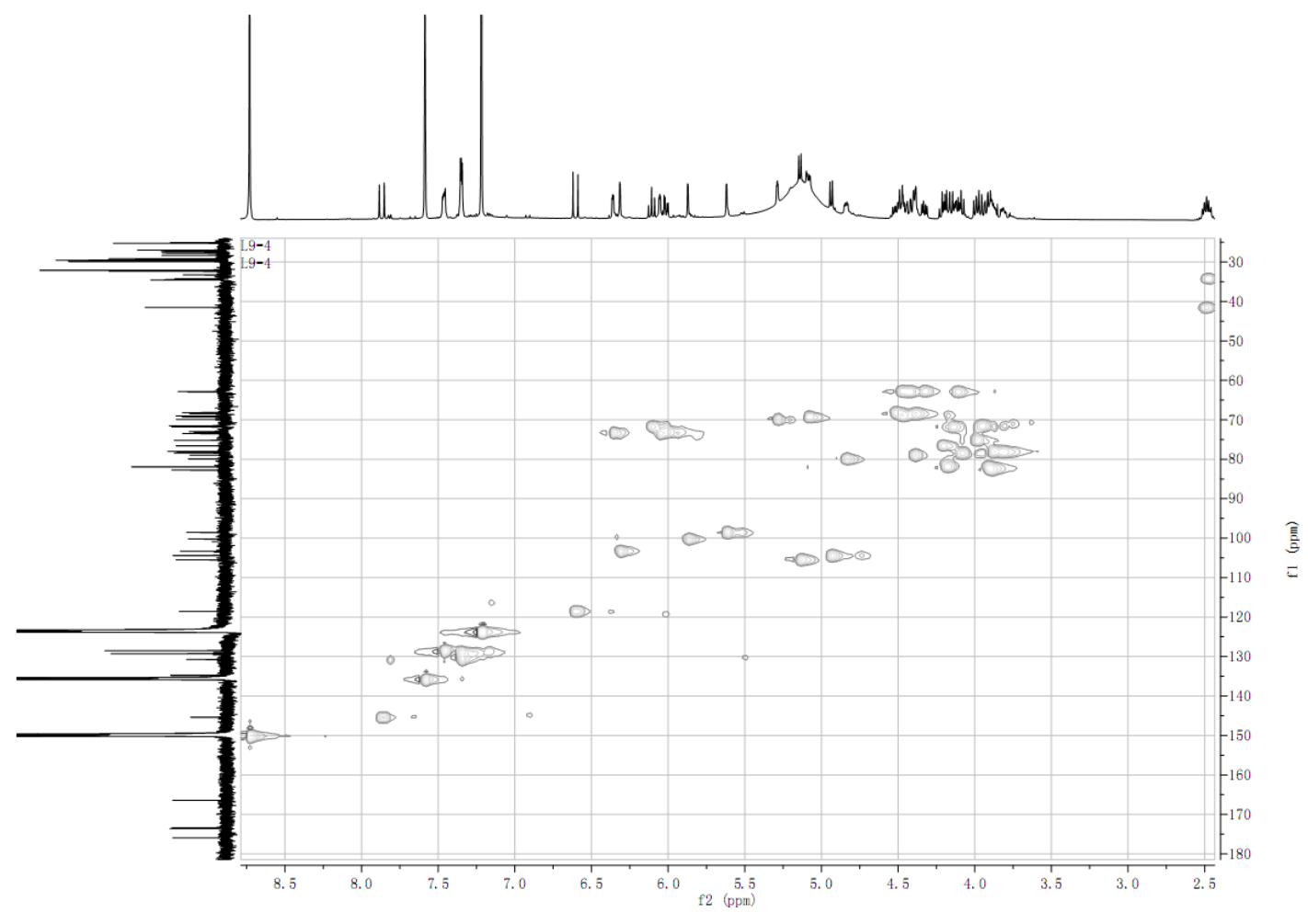

Figure S20. The HSQC spectrum of compound 3

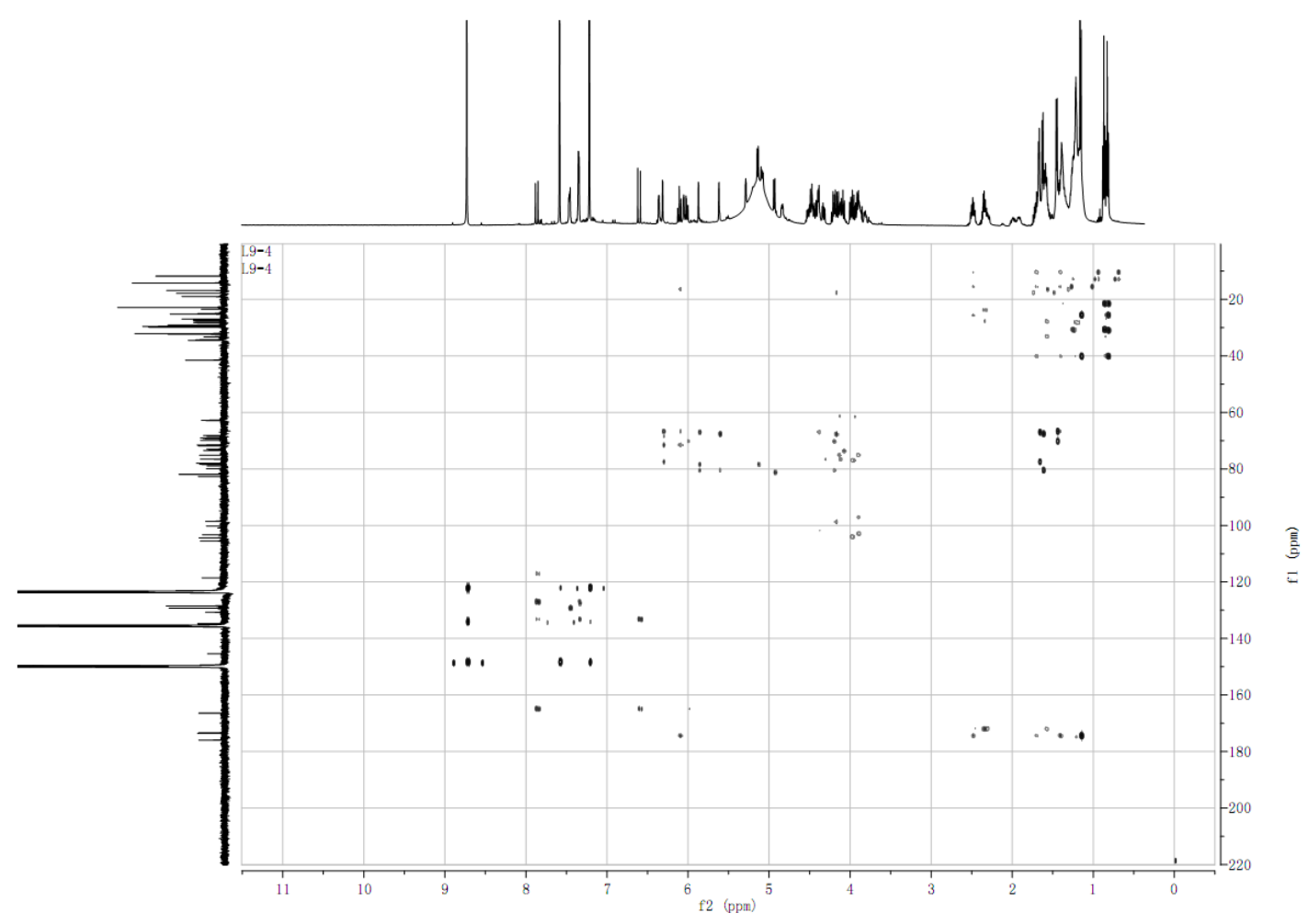

Figure S21. The HMBC spectrum of compound $\mathbf{3}$ 


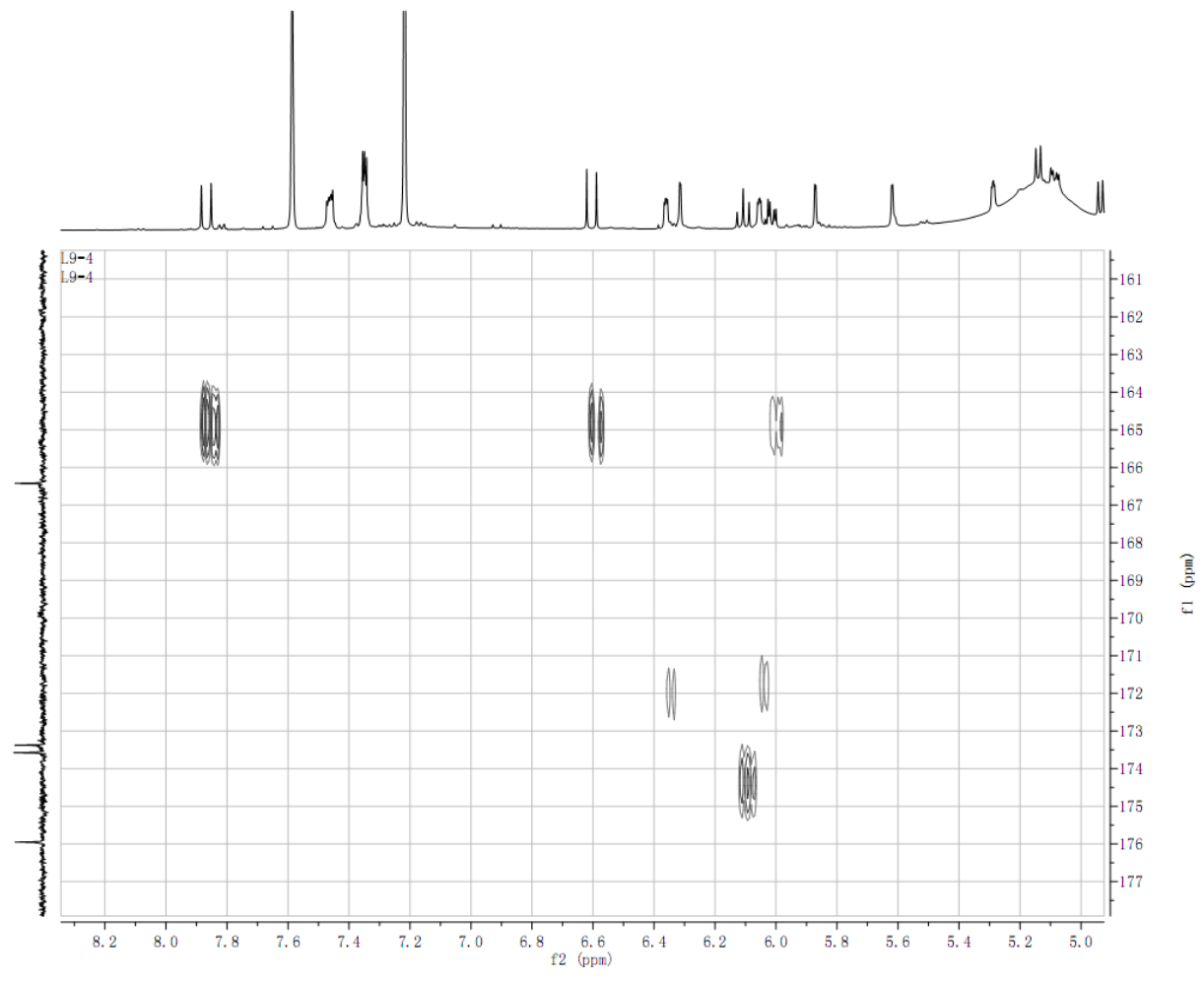

Figure S22. The enlarged HMBC spectrum of compound $\mathbf{3}$

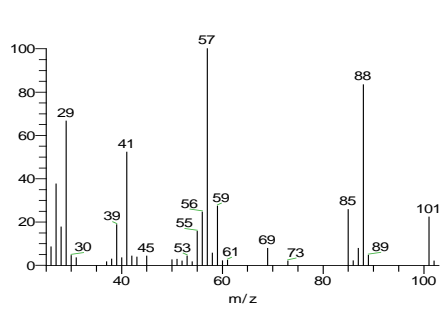
Butanoic acid, 2-methyl-, methyl ester
Formula C6H12O2, MW 116, CASt 868-57-5, Entry\# 23242
Butyric acid, 2-methyl-, methyl ester
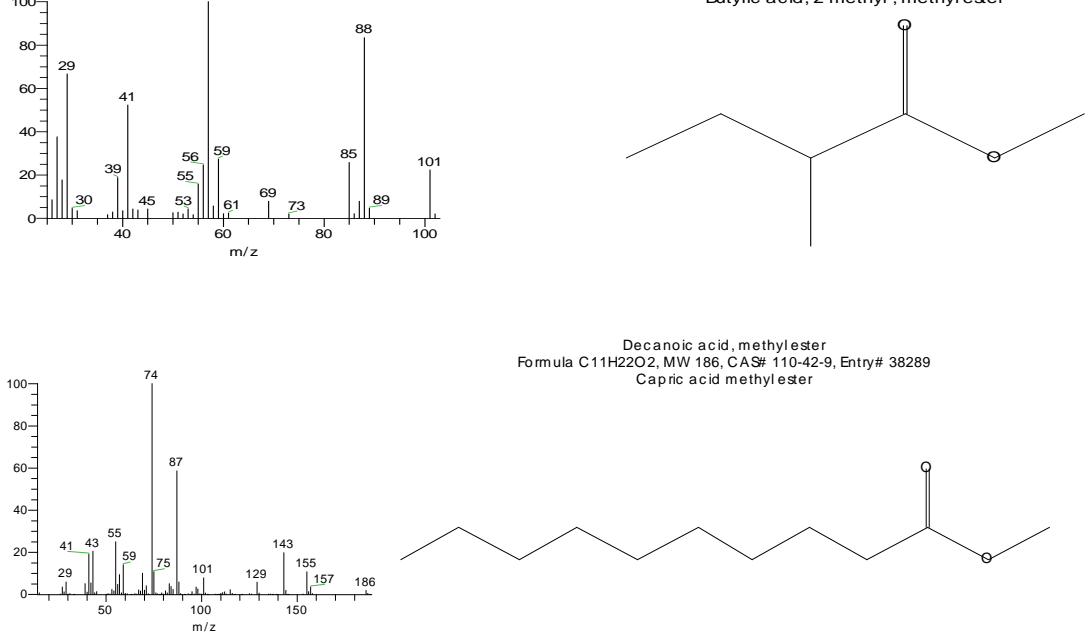

Decanoic acid, methyl ester
Formula C11H22O2, MW 186, CASH 110-42-9, Entry\# 38289 


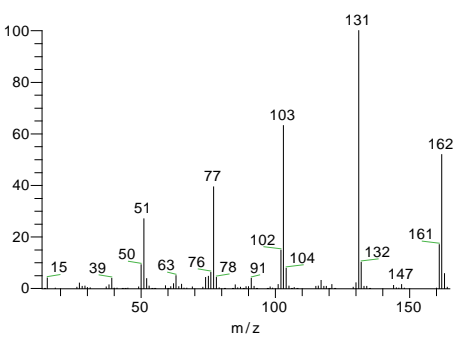

Formula C10H10O2 MW 162 CASH 103-26-4, Entry\# 93436

Cinnamic acid, methylester

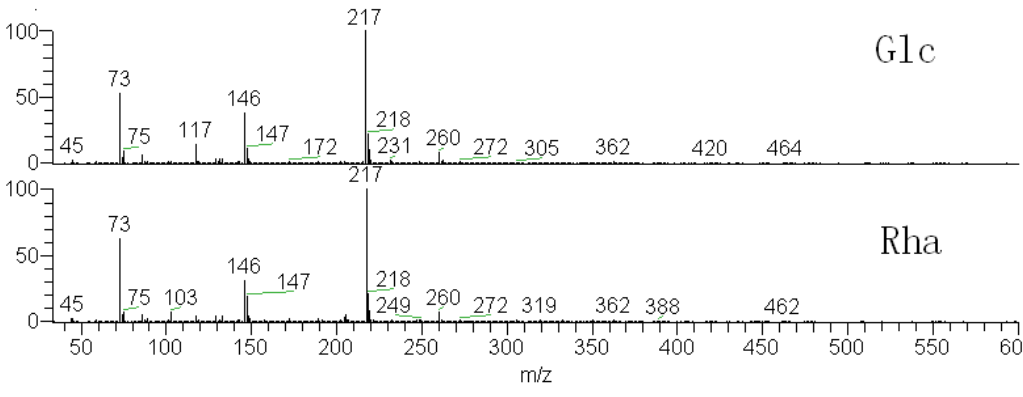

NL: 1.67E7

20141009-1410b0036

5\#1479 RT: 30.12 AV: 1 SB:

$15.00 \mathrm{~F}:$ + c Full ms

[33.00-600.00]

NL: $6.21 \mathrm{E} 6$

20141009-1410b0036

5\#1569 RT: 31.65 AV: 1 SB

$15.00 \mathrm{~F}:+\mathrm{cFull}$ ms

$[33.00-600.00]$

Fig S23. The GC-MS spectral of organic acid and sugar 